\title{
Parâmetros genéticos para caracteres de crescimento em pequizeiro em estádio precoce ${ }^{1}$
}

\author{
Genetic parameters for growth traits in the early stages of the pequi tree
}

\author{
Samuel Cunha Oliveira Giordani*, José Sebastião Cunha Fernandes ${ }^{3}$, Miranda Titon ${ }^{4}$ e Reynaldo Campos \\ Santana $^{4}$
}

\begin{abstract}
Resumo - Parâmetros genéticos estimados por meio de delineamentos genético-estatísticos considerando-se efeitos de populações e progênies são inexistentes para o pequizeiro (Caryocar brasiliense Camb.). O objetivo deste trabalho foi estimar parâmetros genéticos e avaliar a eficiência da seleção baseada em caracteres de crescimento em estádio precoce nesta espécie. O experimento foi instalado em janeiro de 2005, utilizando-se mudas de 31 matrizes originadas de duas procedências, em um delineamento em blocos ao acaso com seis repetições e cinco plantas por parcela, no município de Carbonita, MG. Nos anos de 2005 a 2008 avaliaram-se os caracteres: altura de planta (2005; 2006; 2007 e 2008), diâmetro do caule ao nível do solo (2006; 2007; 2008) e diâmetro da copa (2008). As estimativas da herdabilidade no sentido restrito em nível de indivíduo variaram de 0,15 a 0,50 . As correlações genéticas e fenotípicas entre os caracteres nos diferentes anos foram positivas e em geral altamente significativas. Estimativas da eficiência de seleção obtidas pela expressão de Hamblin e Zimmermann variaram de médias a altas para todos os caracteres. Concluiu-se que, na hipótese de correlação significativa entre os caracteres avaliados e a produção de frutos, a seleção para produção de frutos, baseada em caracteres de crescimento, pode ser iniciada em estádio precoce.
\end{abstract}

Palavras-chave - Caryocar brasiliense. Progênies. Eficiência de seleção. Melhoramento genético.

\begin{abstract}
Genetic parameters estimated through statistical-genetic designs considering population and progeny effects are lacking for the pequi tree (Caryocar brasiliense Camb.). The aim of this study was to estimate genetic parameters and evaluate the efficiency of selection based on growth traits in the early stages. The experiment was carried out in Carbonita, Minas Gerais, Brazil, on January of 2005, using a randomized block design with 31 progenies, six replications and five plants per plot. From 2005 to 2008 the following traits were evaluated: plant height (in 2005; 2006; 2007 and 2008), stem diameter at ground level (in 2006; 2007; 2008) and crown diameter (in 2008). Estimates for narrow-sense heritability at the individual level varied from 0.15 to 0.50 . The genetic and phenotypic correlations between characteristics in the different years were positive and generally highly significant. Estimates of the selection efficiency, obtained using the Hamblin and Zimmermann Expression, ranged from medium to high for all traits. It was concluded that under the premise of a significant correlation between these traits and fruit production, selection for fruit production based on growth traits could be started at an early stage.
\end{abstract}

Key words - Caryocar brasiliense. Progeny. Selection efficiency. Genetic improvement.

\footnotetext{
* Autor para correspondência

${ }^{1}$ Recebido para publicação em 17/12/2010; aprovado em 05/07/2011

Parte da dissertação de Mestrado do primeiro autor, apresentada ao Programa de Pós-Graduação em Produção Vegetal, DAG/UFVJM

${ }^{2}$ Departamento de Ciências Biológicas/FCBS-UFVJM, MGT 367, Km 583, n 5000, Alto da Jacuba, Campus JK, Diamantina-MG, Brasil, 39.100-000, samuel.giordani@ufvjm.edu.br

${ }^{3}$ Departamento de Agronomia/FCA-UFVJM, MGT 367, Km 583, n 5000, Alto da Jacuba, Campus JK, Diamantina-MG, Brasil, 39.100-000, cunha.fernandes@ufvjm.edu.br

${ }^{4}$ Departamento de Engenharia Florestal/FCA-UFVJM, MGT 367, Km 583, n 5000, Alto da Jacuba, Campus JK, Diamantina-MG, Brasil, 39.100-000, titonmiranda@yahoo.com.br, silviculturaufvjm@yahoo.com.br
} 


\section{Introdução}

O pequizeiro (Caryocar brasiliense Camb.) é uma espécie arbórea semidecídua, heliófita e seletiva xerófita pertencente à família Caryocaraceae (SILVA et al., 2001; SOUZA; LORENZI, 2005), que apresenta distribuição por todo o bioma Cerrado ocorrendo principalmente nas regiões Centro Oeste e Sudeste (KERR et al., 2007; SANO; ALMEIDA, 1998).

Seu fruto é muito utilizado na culinária brasileira regional e na indústria agrícola para a extração de óleos e produção de licores(VIEIRA; MARTINS, 2000). Opequizeiro é tido como uma das espécies com potencial medicinal da flora do Cerrado, sendo o fruto e as folhas utilizados para fins terapêuticos (VIEIRA; MARTINS, 2000).

$\mathrm{O}$ pequizeiro distribui-se por quase 2.000 municípios. Estima-se que cerca de 40.000 coletores sobrevivam do extrativismo de seus frutos (KERR et al., 2007), representando uma importante atividade econômica geradora de renda e emprego (FERNANDES et al., 2004; SILVA; MEDEIROS FILHO, 2006). Entretanto, a incorporação recente das áreas de cerrado à agricultura brasileira e a forma extrativista como o pequizeiro tem sido explorado representam grande ameaça à sobrevivência desta espécie bem como das comunidades que dela dependem. Por isso, a importância de um programa de melhoramento com bases genéticas sólidas para o pequizeiro é incontestável, principalmente considerando-se que na literatura não se observam iniciativas neste sentido.

Em um programa de melhoramento, faz-se necessária a instalação de testes de procedências e progênies. Estes têm sido usados na estimação de parâmetros genéticos e seleção de indivíduos, principalmente em espécies florestais (RESENDE, 2002). Para o pequizeiro eles são particularmente importantes, devido à heterogeneidade das condições edafoclimáticas de seus povoamentos naturais, e à grande variação observada entre a idade das plantas que os compõem.

As espécies vegetais perenes apresentam aspectos biológicos peculiares, tais como sobreposição de gerações, longo ciclo reprodutivo, reprodução sexuada e assexuada e expressão dos caracteres ao longo das várias idades (RESENDE, 2002). Portanto a aplicação de metodologias eficientes durante o processo seletivo é de extrema importância (FARIAS NETO et al., 2008). Um aspecto relevante seria a diminuição do tempo necessário para completar um ciclo de seleção, ou seja, promover a seleção na idade juvenil (PEREIRA et al., 1997). Várias alternativas têm sido propostas para se estimar a eficiência da seleção precoce, como por exemplo, a estimativa da correlação genética nas diferentes idades.
Desta forma, a eficiência ou não de uma seleção precoce estará intimamente relacionada com a existência ou não de correlação genética entre os caracteres na idade juvenil e adulta (FALCONER, 1987).

Este trabalho teve por objetivo avaliar a eficiência da seleção baseada em caracteres de crescimento e estimar parâmetros genéticos em progênies de pequizeiro em estádio precoce.

\section{Material e métodos}

O experimento foi conduzido com mudas oriundas de 31 matrizes, sendo cinco da Estação Experimental do Moura - Universidade Federal dos Vales do Jequitinhonha e Mucuri, no município de Curvelo, MG e 26 do Parque Estadual do Rio Preto, no município de São Gonçalo do Rio Preto, MG.

As sementes foram coletadas entre dezembro de 2003 e fevereiro de 2004, após queda natural, nas 31 matrizes previamente selecionadas. Foram escolhidas para matrizes, plantas afastadas entre si de uma distância de pelo menos $50 \mathrm{~m}$. Para evitar o ataque de roedores, as sementes de cada matriz foram colocadas em sacos plásticos permeáveis mantidos pendurados nas mesmas.

Como o número de sementes por matriz e a taxa de germinação destas variaram muito, houve uma variação muito grande no tamanho de cada progênie, ou seja, no número de mudas por matriz. Também não foi possível se obter o mesmo número de matrizes por procedência (população) já que, no referido ano em Curvelo, somente cinco matrizes produziram quantidade suficiente de sementes. Esta variação no tamanho das progênies e das populações teve implicações no processo de estimação dos parâmetros, conforme será mostrado posteriormente.

Em junho de 2004, nas dependências da Fazenda Experimental do Moura, Universidade Federal dos Vales do Jequitinhonha e Mucurí, no município de Curvelo, $\mathrm{MG}$, as sementes foram submetidas a um tratamento de imersão em solução de ácido giberélico a $500 \mathrm{mg} \mathrm{L}$ ${ }^{1}$ por um período de quatro dias. Posteriormente, foram colocadas para germinar a céu aberto, diretamente em sacos plásticos contendo uma mistura de terra de subsolo, esterco e areia na proporção de 2:1:1.

Em dezembro de 2004 as mudas produzidas com as sementes obtidas de cada uma das 31 matrizes, foram transportadas para a área experimental situada na fazenda "Jacú e Arroz" localizada no município de Carbonita, MG, de propriedade da SADA Bio-Energia e Agricultura Ltda., onde permaneceram a céu aberto por aproximadamente um mês e meio. Na última semana de janeiro de 2005 as mudas foram plantadas no campo. 
Os caracteres avaliados foram: a altura da planta (AP - cm) em setembro de 2005 (AP 2005), fevereiro de 2006 (AP 2006), julho de 2007 (AP 2007) e setembro de 2008 (AP 2008); o diâmetro do caule ao nível do solo (DC - mm) em fevereiro de 2006 (DC 2006), julho de 2007 (DC 2007) e setembro de 2008 (DC 2008); e o diâmetro da copa (DCP - cm) apenas em setembro de 2008 (DCP 2008).

O delineamento utilizado para a avaliação das 31 progênies (famílias de meios-irmãos) foi em blocos ao acaso com seis repetições e cinco plantas por parcela, totalizando 930 mudas, plantadas num espaçamento de $2,5 \times 6 \mathrm{~m}$.

Considerando-se o desbalanceamento (variação no número de mudas por matrizes e por população) do experimento pelos motivos explanados anteriormente, os parâmetros e valores genéticos para os caracteres em apreço foram estimados usando-se o Modelo 5 do Programa SELEGEN - REML/BLUP (RESENDE, 2002). Os coeficientes de correlação fenotípicos e genéticos entre os caracteres e anos ao nível de indivíduo e progênies foram estimados a partir dos respectivos valores fenotípicos e genéticos aditivos estimados pelo SELEGEN.

Para se determinar o número de indivíduos (ou progênies) selecionados com base na altura de plantas no ano 2005, coincidentes com os mesmos indivíduos (ou progênies) selecionados com base em qualquer caráter avaliado nos anos subseqüentes, estimou-se a eficiência de seleção (ES) através do método de Hamblin e Zimmermann $(1986)$ onde: $\mathrm{ES}(\%)=(\mathrm{A} / \mathrm{B}-\mathrm{B} / \mathrm{N}) /(1-\mathrm{B} / \mathrm{N})$.

Em que:

$\mathrm{ES}(\%)=$ eficiência da seleção no ano 2005;

A: número de progênies (ou indivíduos) coincidentes nos dois anos;

B: número de progênies (ou indivíduos) selecionados no ano 2005;

$\mathrm{N}$ : número total de progênies (ou indivíduos) da população.

Foram utilizadas as intensidades de seleção de 10 e $20 \%$ para seleção de indivíduos e 20,30 e $65 \%$ para seleção de progênies.

\section{Resultados e discussão}

Observa-se que a variância genética aditiva dentro das populações supera a variância genética aditiva entre elas, para todos os caracteres avaliados e em todos os anos. A Tabela 1 mostra uma clara predominância da variabilidade genética entre matrizes dentro das populações.

Resultados semelhantes foram encontrados também em pequizeiro por Oliveira (1998 apud SANTANA; NAVES, 2003) e Melo Júnior et al. (2004). Estes últimos reportaram a ocorrência de $98 \%$ da variabilidade genética dentro das populações estudadas. Isto reforça a hipótese de que, também para esta espécie, para se maximizar ganhos genéticos e manter a variabilidade genética deve-se tomar menos populações com mais indivíduos por população.

Embora não haja relatos de estimativas de herdabilidade para populações de pequizeiro, em outras espécies tais estimativas são comuns. As estimativas da herdabilidade individual no sentido restrito $\left(\mathrm{h}_{\mathrm{a}}^{2}\right)$ para o caráter AP (TAB. 1) são semelhantes às encontradas para Malpighia emarginata (PAIVA et al., 2002); Eucalyptus grandis e Eucalyptus urophylla (ROCHA et al., 2007); Ocotea porosa (KALIL FILHO et al., 2008); Hymenaea stigonocarpa (MORAES et al., 2008). O mesmo pode ser afirmado para o caráter DC (TAB. 1) em relação aos resultados encontrados para Malpighia emarginata (PAIVA et al., 2002), Hevea brasiliensis (COSTA et al., 2008b) e para Eucalyptus camaldulensis (SANTOS et al., 2008). Maiores divergências são encontradas para o caráter DCP (TAB. 1), onde as estimativas encontradas são bastante divergentes daquelas encontradas em Spondias tuberose (OLIVEIRA et al., 2004); Malpighia emarginata (PAIVA et al., 2002); e Myracrodruon urundeuva (GUERRA et al., 2009).

Embora não muito distante do limite inferior da classificação proposta por Resende (2002) como moderada $\left(0,15<\mathrm{h}^{2}<0,50\right)$, observa-se que o caráter DC 2007 apresenta a menor estimativa de $\mathrm{h}_{\mathrm{a}}^{2}$ (TAB. 1).

Considerando-se as magnitudes das estimativas de $h^{2}$ a para os caracteres em questão (TAB. 1) e lembrando que estas são no sentido restrito e em nível de indivíduo, ganhos genéticos poderão ser conseguidos em caracteres de interesse na fase adulta, caso estes sejam significativamente correlacionados aos primeiros.

A variabilidade ambiental dentro dos blocos ( $\mathrm{c}^{2}$ parc) foi inferior a $5 \%$ para todos os caracteres e anos (TAB. 1). Considerando-se que estimativas em torno de $10 \%$ para caracteres com herdabilidade da ordem de $30 \%$ são consideradas boas para este parâmetro em experimentos com plantas perenes (FARIAS NETO et al., 2008), os presentes resultados implicam em mais um aspecto favorável para a exploração da variabilidade genética dos caracteres em questão. 
Tabela 1 - Estimativas de parâmetros genéticos para os caracteres: altura de planta (cm) em 2005, 2006, 2007 e 2008 (AP2005; AP2006; AP2007; AP2008); diâmetro do caule à altura do solo (mm) em 2006, 2007, 2008 (DC2006, DC2007 e DC2008); e diâmetro da copa $(\mathrm{cm})$ em 2008 (DCP2008)

\begin{tabular}{|c|c|c|c|c|c|c|c|c|}
\hline \multirow{2}{*}{ Parâmetros } & \multicolumn{8}{|c|}{ Caracteres } \\
\hline & AP 2005 & AP 2006 & AP 2007 & AP 2008 & DC 2006 & DC 2007 & DC 2008 & DCP 2008 \\
\hline $\mathrm{Va}$ & 38,23 & 192,00 & 393,31 & 758,66 & 5,34 & 14,09 & 39,09 & 433,96 \\
\hline Vparc & 4,07 & 20,90 & 18,58 & 46,31 & 1,63 & 4,59 & 4,96 & 24,41 \\
\hline Vproc & 8,70 & 77,30 & 180,89 & 351,92 & 1,72 & 3,82 & 20,53 & 370,45 \\
\hline Vê & 55,19 & 428,89 & 924,40 & $1.497,22$ & 21,42 & 75,54 & 129,30 & 1491,68 \\
\hline Vf & 106,19 & 719,10 & $1.517,18$ & $2.654,12$ & 30,11 & 98,03 & 193,87 & $2.320,50$ \\
\hline $\mathrm{h}_{\mathrm{a}}^{2}$ & 0,36 & 0,27 & 0,26 & 0,29 & 0,18 & 0,14 & 0,20 & 0,19 \\
\hline $\mathrm{c}^{2}$ parc & 0,04 & 0,03 & 0,01 & 0,02 & 0,05 & 0,05 & 0,03 & 0,01 \\
\hline$c^{2}$ proc & 0,08 & 0,11 & 0,12 & 0,13 & 0,06 & 0,04 & 0,11 & 0,16 \\
\hline CVgi\% & 27,90 & 20,96 & 19,83 & 21,78 & 16,54 & 16,84 & 17,89 & 27,92 \\
\hline CVgp $\%$ & 13,95 & 10,48 & 9,92 & 10,89 & 8,27 & 8,14 & 8,95 & 13,96 \\
\hline $\mathrm{CVe} \%$ & 20,60 & 17,61 & 16,20 & 16,95 & 18,55 & 20,95 & 17,33 & 26,40 \\
\hline Média Geral & 22,16 & 66,10 & 99,99 & 126,44 & 13,97 & 22,30 & 34,94 & 74,61 \\
\hline IC $\left(h^{2}{ }_{a}\right)$ & 0,11 & 0,10 & 0,10 & 0,10 & 0,08 & 0,07 & 0,09 & 0,08 \\
\hline
\end{tabular}

Va: variância genética aditiva; Vparc: variância ambiental entre parcelas; Vproc: variância genética entre procedências ou populações; Vê: variância residual; Vf: variância fenotípica individual; $\mathrm{h}_{\mathrm{a}}^{2}$ : herdabilidade individual no sentido restrito; $\mathrm{c}^{2}$ parc: coeficiente de determinação dos efeitos de parcela; c $^{2}$ proc: coeficiente de determinação dos efeitos de populações ou procedências; CVgi\%: coeficiente de variação genética aditiva individual; CVgp\%:

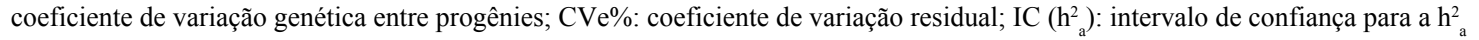

Estimativas de coeficientes de variação genética aditiva individual (CVgi\%) podem ser observadas na literatura para algumas espécies como Hevea brasiliensis (COSTA et al., 2008a), Ocotea porosa (KALIL FILHO et al., 2008) e Hymenaea stigonocarpa (MORAES et al., 2008) para o caráter AP; e Pinus caribaea (MORAES et al., 2007), Hevea brasiliensis (COSTA et al., 2008a, 2008b) e Myracrodruon urundeuva (GUERRA et al., 2009) para o caráter DC. Embora em espécies diferentes do pequizeiro, tais estimativas têm magnitudes semelhantes às encontradas no presente trabalho (TAB. 1). Tais considerações são válidas também para os coeficientes de variação genética entre progênies (CVgp\%) já que estes são a metade do CVgi\% (TAB. 1). Para o caráter DCP, foi encontrado na literatura uma estimativa para Myracrodruon urundeuva (DURIGAN et al., 2008) porém, o valor é inferior ao encontrado neste trabalho.

A razão entre $\mathrm{CVgi} \%$ e o coeficiente de variação experimental ( $\mathrm{CVe} \%)$ costuma também ser usada como indicador de progresso com seleção, sendo a expectativa deste progresso promissora quando esta razão está acima da unidade (VENCOVSKY, 1992; FALCONER,
1987). No presente trabalho observa-se que apenas os caracteres DC 2006 e DC 2007 apresentam esta razão abaixo, mas mesmo assim, próximo da unidade.

$\mathrm{Na}$ Tabela 2 encontram-se as estimavas dos coeficientes de correlação fenotípica e genética entre caracteres e anos considerando-se as médias de todas as progênies. Observa-se que são todas positivas e significativas. Estas estimativas tiveram seus valores reduzidos ao se considerarem apenas as 20 progênies mais altas (intensidade de seleção $=65 \%$ ) no ano 2005 , sendo a queda maior para as correlações genéticas, alguns valores chegando a não ser significativos (TAB. 3).

As mesmas ponderações podem ser feitas para as estimativas destas correlações em nível de indivíduo, exceto pelo fato de que neste último caso as estimativas das correlações genéticas são superiores às fenotípicas (TAB. 4; TAB. 5).

Estimativas de correlações fenotípicas e genéticas para caracteres de crescimento são encontradas em outras espécies (COSTA et al., 2008a; ETTORI et al., 2004; FARIAS NETO, 1999; MORAES et al., 2007; PAIVA et al., 2002), mas não em pequizeiro. 
Tabela 2 - Correlações fenotípicas e genéticas em nível de média de progênies, sem seleção, quanto à altura de planta - AP (cm), diâmetro do caule à altura do solo - DC $(\mathrm{mm})$ e diâmetro da copa - DCP $(\mathrm{cm})$, avaliados nos anos 2005 a 2008

\begin{tabular}{|c|c|c|c|c|c|c|c|c|}
\hline & AP05 & AP06 & AP07 & AP08 & DC06 & DC07 & DC08 & DCP08 \\
\hline AP05 & - & $0,87 * *$ & $0,73 * *$ & $0,73 * *$ & $0,86^{* *}$ & $0,69 * *$ & $0,69 * *$ & $0,74 * *$ \\
\hline AP06 & $0,81 * *$ & - & $0,86 * *$ & $0,84 * *$ & $0,91 * *$ & $0,81 * *$ & $0,82 * *$ & $0,83^{* *}$ \\
\hline AP07 & $0,71 * *$ & $0,88^{* *}$ & - & $0,92 * *$ & $0,84 * *$ & $0,91 * *$ & $0,90 * *$ & $0,88^{* *}$ \\
\hline AP08 & $0,65 * *$ & $0,84 * *$ & $0,91 * *$ & - & $0,78^{* *}$ & $0,84 * *$ & $0,92 * *$ & $0,91 * *$ \\
\hline DC06 & $0,81 * *$ & $0,83 * *$ & $0,72 * *$ & $0,65 * *$ & - & $0,84 * *$ & $0,80 * *$ & $0,76^{* *}$ \\
\hline DC07 & $0,69 * *$ & $0,80 * *$ & $0,78 * *$ & $0,72 * *$ & $0,86^{* *}$ & - & $0,90 * *$ & $0,84 * *$ \\
\hline DC08 & $0,60 * *$ & $0,74 * *$ & $0,79 * *$ & $0,83 * *$ & $0,68^{* *}$ & $0,87 * *$ & - & $0,91 * *$ \\
\hline DCP08 & $0,64 * *$ & $0,72 * *$ & $0,75^{* *}$ & $0,79 * *$ & $0,51 * *$ & $0,62 * *$ & $0,80 * *$ & - \\
\hline
\end{tabular}

Correlações fenotípicas acima da diagonal e correlações genéticas abaixo da diagonal; **: significativo a $1 \%$ pelo teste $\mathrm{F}$

Tabela 3 - Correlações fenotípicas e genéticas em nível de média de progênies, com seleção, quanto à altura de planta - AP (cm), diâmetro do caule à altura do solo - DC $(\mathrm{mm})$ e diâmetro da copa - DCP $(\mathrm{cm})$, avaliados nos anos 2005 a 2008

\begin{tabular}{|c|c|c|c|c|c|c|c|c|}
\hline & AP05 & AP06 & AP07 & AP08 & DC06 & DC07 & DC08 & DCP08 \\
\hline AP05 & - & $0,82 * *$ & $0,63 * *$ & $0,67 * *$ & $0,79 * *$ & $0,61 * *$ & $0,65 * *$ & $0,71 * *$ \\
\hline AP06 & $0,67 * *$ & - & $0,80 * *$ & $0,81 * *$ & $0,85 * *$ & $0,77 * *$ & $0,81 * *$ & $0,82 * *$ \\
\hline AP07 & $0,52 * *$ & $0,84 * *$ & - & $0,89 * *$ & $0,78 * *$ & $0,88^{* *}$ & $0,87 * *$ & $0,83^{* *}$ \\
\hline AP08 & $0,43 * *$ & $0,78 * *$ & $0,86^{* *}$ & - & $0,73 * *$ & $0,78^{* *}$ & $0,87 * *$ & $0,86^{* *}$ \\
\hline DC06 & $0,64 * *$ & $0,68 * *$ & $0,50 * *$ & $0,39^{*}$ & - & $0,84 * *$ & $0,81 * *$ & $0,71 * *$ \\
\hline DC07 & $0,42 * *$ & $0,63 * *$ & $0,63 * *$ & $0,50 * *$ & $0,76^{* *}$ & - & $0,87 * *$ & $0,77 * *$ \\
\hline DC08 & $0,29^{\mathrm{ns}}$ & $0,59 * *$ & $0,65 * *$ & $0,72 * *$ & $0,42 * *$ & $0,77 * *$ & - & $0,86^{* *}$ \\
\hline DCP08 & $0,29^{\mathrm{ns}}$ & $0,54 * *$ & $0,58 * *$ & $0,68^{* *}$ & $0,06^{\mathrm{ns}}$ & $0,27^{\mathrm{ns}}$ & $0,63 * *$ & - \\
\hline
\end{tabular}

Correlações fenotípicas acima da diagonal e correlações genéticas abaixo da diagonal; ns, ${ }^{*}$ e ** : não significativo, significativo a $5 \%$ e $1 \%$, respectivamente, pelo teste F; Intensidade de seleção $=65 \%$ (20 progênies)

Tabela 4 - Correlações fenotípicas e genéticas em nível de indivíduos, sem seleção, quanto à altura de planta - AP (cm), diâmetro do caule à altura do solo - DC (mm) e diâmetro da copa - DCP $(\mathrm{cm})$, avaliados nos anos 2005 a 2008

\begin{tabular}{|c|c|c|c|c|c|c|c|c|}
\hline & AP05 & AP06 & AP07 & AP08 & DC06 & DC07 & DC08 & DCP08 \\
\hline AP05 & - & $0,78^{* *}$ & $0,65^{* *}$ & $0,56 * *$ & $0,77 * *$ & $0,63 * *$ & $0,55^{* *}$ & $0,49 * *$ \\
\hline AP06 & $0,84 * *$ & - & $0,86^{* *}$ & $0,79 * *$ & $0,87 * *$ & $0,81 * *$ & $0,76^{* *}$ & $0,68^{* *}$ \\
\hline AP07 & $0,73 * *$ & $0,91 * *$ & - & $0,87 * *$ & $0,78 * *$ & $0,85 * *$ & $0,82 * *$ & $0,74 * *$ \\
\hline AP08 & $0,67 * *$ & $0,87 * *$ & $0,94 * *$ & - & $0,71 * *$ & $0,80 * *$ & $0,89 * *$ & $0,80 * *$ \\
\hline DC06 & $0,84 * *$ & $0,86^{* *}$ & $0,75^{* *}$ & $0,67 * *$ & - & $0,84 * *$ & $0,76^{* *}$ & $0,64 * *$ \\
\hline DC07 & $0,72 * *$ & $0,84 * *$ & $0,82 * *$ & $0,75^{* *}$ & $0,88 * *$ & - & $0,90 * *$ & $0,80 * *$ \\
\hline DC08 & $0,61 * *$ & $0,77 * *$ & $0,82 * *$ & $0,86 * *$ & $0,70 * *$ & $0,90 * *$ & - & $0,87 * *$ \\
\hline DCP08 & $0,67 * *$ & $0,75 * *$ & $0,78 * *$ & $0,82 * *$ & $0,54 * *$ & $0,67 * *$ & $0,84 * *$ & - \\
\hline
\end{tabular}

Correlações fenotípicas acima da diagonal e correlações genéticas abaixo da diagonal; **: significativo a $1 \%$ pelo teste $\mathrm{F}$ 
Tabela 5 - Correlações fenotípicas e genéticas em nível de indivíduos, com seleção, quanto à altura de planta - AP (cm), diâmetro do caule à altura do solo - DC (mm) e diâmetro da copa - DCP $(\mathrm{cm})$, avaliados nos anos 2005 a 2008

\begin{tabular}{|c|c|c|c|c|c|c|c|c|}
\hline & AP05 & AP06 & AP07 & AP08 & DC06 & DC07 & DC08 & DCP08 \\
\hline AP05 & - & $0,51 * *$ & $0,40 * *$ & $0,23 * *$ & $0,48 * *$ & $0,28 * *$ & $0,25^{* *}$ & $0,25^{* *}$ \\
\hline AP06 & $0,53^{* *}$ & - & $0,71 * *$ & $0,56^{* *}$ & $0,58^{* *}$ & $0,50 * *$ & $0,48 * *$ & $0,42 * *$ \\
\hline AP07 & $0,32 * *$ & $0,81 * *$ & - & $0,77 * *$ & $0,44 * *$ & $0,65 * *$ & $0,61 * *$ & $0,54 * *$ \\
\hline AP08 & $0,16^{*}$ & $0,69 * *$ & $0,83 * *$ & - & $0,39 * *$ & $0,62 * *$ & $0,76^{* *}$ & $0,64 * *$ \\
\hline DC06 & $0,45^{* *}$ & $0,53^{* *}$ & $0,41 * *$ & $0,31 * *$ & - & $0,69 * *$ & $0,56^{* *}$ & $0,43 * *$ \\
\hline DC07 & $0,23^{* *}$ & $0,50^{* *}$ & $0,49 * *$ & $0,45^{* *}$ & $0,78 * *$ & - & $0,84 * *$ & $0,68 * *$ \\
\hline DC08 & $0,04 \mathrm{~ns}$ & $0,28 * *$ & $0,49 * *$ & $0,47 * *$ & $0,25^{* *}$ & $0,39 * *$ & - & $0,81 * *$ \\
\hline DCP08 & $0,19 * *$ & $0,54 * *$ & $0,56^{* *}$ & $0,65 * *$ & $0,25 * *$ & $0,45 * *$ & $0,45 * *$ & - \\
\hline
\end{tabular}

Correlações fenotípicas acima da diagonal e correlações genéticas abaixo da diagonal; ns ${ }^{*}$ e **: não significativo, significativo a $5 \%$ e $1 \%$, respectivamente, pelo teste F; Intensidade de seleção $=20 \%$ (178 indivíduos)

De forma geral, com base nas estimativas destas correlações para o grupo selecionado, tanto em nível de indivíduo como de progênie (TAB. 3; TAB. 5), podese concluir que ganhos genéticos podem ser obtidos em anos subseqüentes para os caracteres AP, DC e DCP quando a seleção é praticada no caráter AP em 2005. Tal conclusão leva à inferência de que ganhos genéticos podem ser obtidos também para outros caracteres como a produção de frutos, caso estes sejam geneticamente correlacionados a caracteres de crescimento.

Uma abordagem mais sólida para o ganho genético com seleção se refere à proporção dos indivíduos ou famílias selecionados em determinado caráter e ano, que se manterá entre os selecionados quando esta seleção for feita tendo como base o mesmo ou outro caráter em anos subseqüentes. Quando se faz uma correção para as coincidências que podem ocorrer ao acaso, tal procedimento denomina-se eficiência de seleção (HAMBLIN; ZIMMERMANN, 1986).

$\mathrm{Na}$ Tabela 6 encontram-se as estimativas da eficiência de seleção quando esta é praticada no caráter AP no ano 2005, tanto em nível de indivíduos como de famílias, considerando-se as intensidades de seleção de 10 e $20 \%$ para indivíduos e 20,30 e $65 \%$ para famílias, respectivamente. Não surpreende a constatação de que há uma perda de eficiência, para seleção individual nos caracteres AP e DC, na medida em que se aumenta o intervalo de tempo entre o ano onde a seleção é praticada e o ano onde o ganho é avaliado.

O mesmo não acontece ao se confrontar, na intensidade de seleção de $10 \%$, as eficiências médias de seleção para os caracteres AP e DC, onde a eficiência para o segundo é praticamente o dobro da eficiência para o primeiro (TAB. 6). Esta constatação torna-se mais surpreendente quando se observa a Tabela 5, onde a média das estimativas de correlações fenotípicas entre AP05 e este mesmo caráter nos anos subseqüentes $(0,38)$ é superior à média destas mesmas estimativas entre AP05 e o caráter DC nos anos subseqüentes $(0,34)$. O mesmo é constatado para as estimativas de correlações genéticas onde estas médias são 0,34 e 0,24 , respectivamente.

Aparentemente contraditória também é a observação, principalmente para a seleção entre progênies, de que a eficiência de seleção não necessariamente aumenta quando a intensidade de seleção se torna mais branda (TAB. 6). Considerandose ainda a Tabela 6 observa-se que, para a seleção em nível de indivíduo, a intensidade de seleção de $20 \%$ promove eficiências de seleção mais consistentes nos anos subseqüentes tanto para AP quanto para DC e DCP. Já para seleção entre progênies esta consistência só se verifica na intensidade de seleção de $30 \%$ para os caracteres AP e DC. Para o caráter DCP a eficiência da seleção é maior para a intensidade de seleção de $65 \%$.

A eficiência de seleção proposta por Hamblin e Zimmermann (1986) mostra-se, pela sua concepção, o melhor indicador a ser considerado quando se trabalha com resposta correlacionada. A confiabilidade deste método vem do fato de que nele há um confronto direto entre as unidades (indivíduos ou progênies) selecionadas com base em um caráter e as unidades selecionadas com base em outro caráter, o que não acontece com os coeficientes de correlação fenotípicos e genéticos. 
Tabela 6 - Eficiência de seleção sobre o caráter Altura de Planta $(\mathrm{cm})$ no ano 2005, para as intensidades de seleção entre indivíduos de $10 \%$ e $20 \%$ e entre famílias de $20 \%, 30 \%$ e $65 \%$, e resposta nos caracteres Altura de Planta (cm) e Diâmetro do Caule (mm) no nível do solo nos anos 2006, 2007 e 2008 e no caráter Diâmetro da Copa (cm) no ano 2008

\begin{tabular}{|c|c|c|c|c|c|c|c|c|c|}
\hline & \multirow[b]{2}{*}{ IS } & \multicolumn{3}{|c|}{-------Altura de Planta-------- } & \multicolumn{3}{|c|}{-------Diâmetro do Caule-------- } & \multicolumn{2}{|c|}{----Diâmetro da Copa---- } \\
\hline & & Anos & $\mathrm{ES}(\%)$ & Média & Anos & $\mathrm{ES}(\%)$ & Média & Anos & ES (\%) \\
\hline \multirow{6}{*}{ 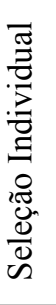 } & $10 \%$ & $2005-2006$ & 60,86 & & $2005-2006$ & 100,00 & & - & - \\
\hline & $10 \%$ & $2005-2007$ & 45,71 & 45,71 & 2005-2007 & 92,42 & 89,47 & - & - \\
\hline & $10 \%$ & $2005-2008$ & 30,56 & & 2005-2008 & 76,00 & & $2005-2008$ & 77,27 \\
\hline & $20 \%$ & $2005-2006$ & 87,36 & & 2005-2006 & 92,25 & & - & - \\
\hline & $20 \%$ & $2005-2007$ & 85,25 & 82,68 & 2005-2007 & 87,32 & 84,03 & - & - \\
\hline & $20 \%$ & $2005-2008$ & 75,42 & & 2005-2008 & 72,52 & & $2005-2008$ & 73,22 \\
\hline \multirow{9}{*}{ 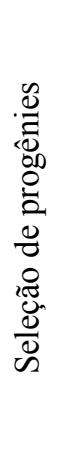 } & $20 \%$ & $2005-2006$ & 58,85 & & $2005-2006$ & 58,70 & & - & - \\
\hline & $20 \%$ & $2005-2007$ & 38,27 & 51,99 & 2005-2007 & 17,30 & 38,00 & - & - \\
\hline & $20 \%$ & $2005-2008$ & 58,85 & & $2005-2008$ & 38,00 & & $2005-2008$ & 17,30 \\
\hline & $30 \%$ & $2005-2006$ & 70,59 & & $2005-2006$ & 85,20 & & - & - \\
\hline & $30 \%$ & $2005-2007$ & 55,88 & 60,78 & 2005-2007 & 70,50 & 65,57 & - & - \\
\hline & $30 \%$ & $2005-2008$ & 55,88 & & $2005-2008$ & 41,00 & & $2005-2008$ & 17,30 \\
\hline & $65 \%$ & 2005-2006 & 55,36 & & 2005-2006 & 41,00 & & - & - \\
\hline & $65 \%$ & $2005-2007$ & 55,36 & 55,36 & $2005-2007$ & 55,70 & 45,90 & - & - \\
\hline & $65 \%$ & $2005-2008$ & 55,36 & & $2005-2008$ & 41,00 & & $2005-2008$ & 70,50 \\
\hline
\end{tabular}

IS - Intensidade de Seleção; ES (\%) - Eficiência da seleção proposta por Hamblin e Zimmerman (1986) em porcentagem

Finalmente, considerando-se ainda os dados da Tabela 6, pode-se concluir que, para a produção de frutos, que é o caráter ainda não avaliado e de maior interesse na espécie em estudo, qualquer inferência deve ser cautelosa. Por outro lado, a seleção para altura de plantas com um ano de idade, com vistas a ganhos na produção de frutos na fase adulta, só poderia ser considerada totalmente inviável se as estimativas das eficiências de Hamblin e Zimmermann, (1986) fossem muito baixas. Esta assertiva parece válida principalmente quando se observa as estimativas das eficiências para o caráter Diâmetro da Copa (possivelmente o mais correlacionado com a produção de frutos) em 2008, quando a seleção é conduzida, em nível de indivíduos, no caráter altura de planta em 2005: as ES são superiores a $70 \%$ para ambas as intensidades de seleção consideradas.

\section{Conclusões}

1. Estimativas de parâmetros genéticos indicam que há variabilidade genética significativa para caracteres de crescimento em plantas de pequizeiro na fase juvenil;

2. A estimativa da eficiência da seleção é uma ferramenta promissora e poderá ser utilizada para auxiliar na seleção precoce de plantas superiores;
3. A seleção baseada em caracteres de crescimento poderá ser eficiente no melhoramento genético do pequizeiro, discriminando precocemente progênies e indivíduos com melhor potencial para produção de frutos ou outras características de interesse, caso estejam correlacionadas a esses caracteres.

\section{Agradecimentos}

À SADA Bio-Energia e Agricultura Ltda pelo apoio financeiro e logístico; à Coordenação de Aperfeiçoamento de Pessoal de Nível Superior(CAPES) pela concessão de bolsa; à Fundação de Amparo à Pesquisa do estado de Minas Gerais (FAPEMIG) e à UFVJM, a instituição que concedeu o maior apoio.

\section{Referências}

COSTA, R. B. et al. Seleção simultânea para porte reduzido e alta produção de látex em seringueira. Bragantia, v. 67, n. 03, p. 649-654, 2008a.

COSTA, R. B. et al. Variabilidade genética e seleção para caracteres de crescimento da seringueira. Bragantia, v. 67, n. 02 , p. 299-305, 2008b. 
DURIGAN, M R. et al. Variação genética em progênies de Mabea fistulifera Mart. em sistema de plantio misto na região de Selvíria - MS. In: SIMPÓSIO NACIONAL CERRADO, 9., 2008, Brasília. Anais eletrônicos... Brasília: EMBRAPA, 2008. Disponível em: <http://simposio.cpac.embrapa.br/ simposio_pc210/fichas/00729_trab1_ficha.pdf>. Acesso em: 15 abr. 2010.

ETTORI, L. C.; SATO, A. S.; SHIMIZU, J. Y. Variação genética em procedências mexicanas de Pinus maximinoi. Revista do Instituto Florestal, v. 16, n. 01, p. 01-09, 2004.

FALCONER, D. S. Introdução à genética quantitativa. Viçosa: UFV, 1987. 279 p.

FARIAS NETO, J. T. Estimativas de parâmetros genéticos em progênies de meio-irmãos de pupunheira. Boletim de Pesquisa Florestal Colombo, n. 39, p. 109-117, 1999.

FARIAS NETO, J. T. et al. Estimativas de parâmetros genéticos e ganhos de seleção em progênies de polinização aberta de açaizeiro. Revista Brasileira de Fruticultura, v. 30, n. 04, p. 1051-1056, 2008.

FERNANDES, L. C. et al. Abundância de insetos herbívoros associados ao pequizeiro (Caryocar brasiliense Cambess). Revista Árvore, v. 28, n. 06, p. 919-924, 2004.

GUERRA, C. R. S. B. et al. Estratégias de seleção dentro de progênies em duas populações de Myracrodruon urundeuva Fr. All. Scientia Forestalis, v. 37, n. 81, p. 79-87, 2009.

HAMBLIN, J.; ZIMMERMAN, M. J. O. Breeding common bean for yield mixtures. Plant Breeding Reviews, v. 04, p. 245-272, 1986.

KALIL FILHO, A. N. et al. Pré-melhoramento de populações de imbuia. Pesquisa Florestal Brasileira, n. 57, p. 61-67, 2008.

KERR, W. E.; SILVA, F. R.; TCHUCARRAMAE, B. Pequi (Caryocar Brasiliense Camb.) informações preliminares sobre um pequi sem espinhos no caroço. Revista Brasileira de Fruticultura, v. 29, n. 01, p. 169-171, 2007.

MELO JÚNIOR, A. F. et al. Estrutura genética de populações naturais de pequizeiro (Caryocar brasiliense Camb.). Scientia Florestalis, n. 66, p. 56-65, 2004.

MORAES, M. A. et al. Variação genética e ganho da seleção em progênies de uma população natural de Hymenaea stigonocarpa Mart ex Hayne. In: SIMPÓSIO NACIONAL CERRADO, 9., 2008, Brasília. Anais eletrônicos... Brasília: EMBRAPA, 2008. Disponível em: $<$ http://www.cpac.embrapa.br/publicacoes/search pbl/1?q=MORAES,\%20J.\%20M.>. Acesso em: 15 abr. 2010.

MORAES, M. L. T. et al. Efeito do desbaste seletivo nas estimativas de parâmetros genéticos em progênies de Pinus caribaea Morelet var. hondurensis. Scientia Florestalis, n. 74, p. 55-65, 2007.
OLIVEIRA, V. R. et al. Variabilidade genética de procedências e progênies de umbuzeiro via metodologia de modelos lineares mistos (REML/BLUP). Revista Brasileira de Fruticultura, v. 26, n. 01, p. 53-56, 2004.

PAIVA, J. R.; RESENDE, M. D. V.; CORDEIRO, E. R. Índice multiefeitos e estimativas de parâmetros genéticos em aceroleira. Pesquisa Agropecuária Brasileira, v. 37, n. 06, p. 799-807, 2002.

PEREIRA, A. B. et al. Eficiência da seleção precoce em famílias de meios irmãos de Eucalyptus camaldulensis dehnh., avaliadas na região noroeste do Estado de Minas Gerais. Revista Cerne, v. 03, n. 01, p. 67-81, 1997.

RESENDE, M. D. V. Genética biométrica e estatística no melhoramento de plantas perenes. Brasília: EMBRAPA, 2002. $975 \mathrm{p}$.

ROCHA, M. G. B. et al. Seleção de genitores de Eucalyptus grandis e de Eucalyptus urophylla para a produção de híbridos interespecíficos utilizando REML/BLUP e informação de divergência genética. Revista Árvore, v. 31, n. 06, p. 977-987, 2007.

SANO, S. M; ALMEIDA, S. P. Cerrado: ambiente e flora. Planaltina: EMBRAPA, 1998. 556 p.

SANTANA, J. G.; NAVES, R. V. Caracterização de ambientes de cerrado com alta densidade de pequizeiros (Caryocar brasiliense camb.) na região sudeste do Estado de Goiás. Pesquisa Agropecuária Tropical, v. 33, n. 01, p. 01-10, 2003.

SANTOS, F. W. et al. Variação genética para a densidade básica da madeira e caracteres silviculturais em uma população base de Eucalyptus camaldulensis Dehnh. Revista do Instituto Florestal, v. 20, n. 02, p. 185-194, 2008.

SILVA, D. B. et al. Avaliação do potencial de produção do "pequizeiro-anão" sob condições naturais na região sul do Estado de Minas Gerais. Revista Brasileira de Fruticultura, v. 23, n. 03, p. 726-729, 2001.

SILVA, M. A. P.; MEDEIROS FILHO, S. Emergência de plântulas de pequi (Caryocar coriaceum Wittm). Revista Ciência Agronômica, v. 37, n. 03, p. 381-385, 2006.

SOUZA, V. C.; LORENZI, H. Botânica sistemática: guia ilustrado para identificação das famílias de angiospermas da flora brasileira, baseado em APG II. Nova Odessa: Instituto Plantarum, 2005. $611 \mathrm{p}$.

VENCOVSKY, R. B. P. Genética biométrica no fitomelhoramento. Ribeirão Preto: Sociedade Brasileira de Genética, 1992. 496 p.

VIEIRA, R. F., MARTINS, M. V. M. Recursos genéticos de plantas medicinais do cerrado: uma compilação de dados. Revista Brasileira de Plantas Medicinais, v. 03, n. 01, p. 13-36, 2000. 